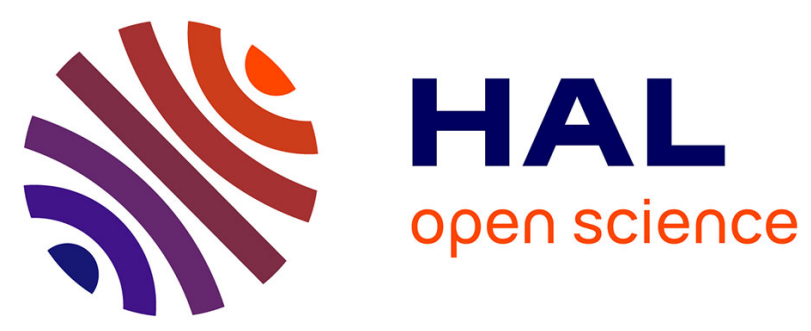

\title{
Regulatory analysis of potential candidate bands for the modernisation of GNSS systems in 2015-2020
}

\author{
Paul Thevenon, Michel Bousquet, Christophe Macabiau, Thomas Grelier, \\ Lionel Ries, Daniel Roviras
}

\section{- To cite this version:}

Paul Thevenon, Michel Bousquet, Christophe Macabiau, Thomas Grelier, Lionel Ries, et al.. Regulatory analysis of potential candidate bands for the modernisation of GNSS systems in 2015-2020. IWSSC 2008, IEEE International Workshop on Satellite and Space Communications, Oct 2008, Toulouse, France. pp 172-175, 10.1109/IWSSC.2008.4656778 . hal-01022446

\section{HAL Id: hal-01022446 \\ https://hal-enac.archives-ouvertes.fr/hal-01022446}

Submitted on 30 Sep 2014

HAL is a multi-disciplinary open access archive for the deposit and dissemination of scientific research documents, whether they are published or not. The documents may come from teaching and research institutions in France or abroad, or from public or private research centers.
L'archive ouverte pluridisciplinaire HAL, est destinée au dépôt et à la diffusion de documents scientifiques de niveau recherche, publiés ou non, émanant des établissements d'enseignement et de recherche français ou étrangers, des laboratoires publics ou privés. 


\section{Regulatory Analysis of Potential Candidate Bands for the Modernisation of GNSS Systems in 2015-2020}

\author{
Paul Thevenon, Michel Bousquet \\ TeSA-ISAE \\ Toulouse, France
}

\author{
Christophe Macabiau \\ ENAC \\ Toulouse, France
}

\author{
Thomas Grelier, Lionel Ries \\ CNES \\ Toulouse, France
}

\author{
Daniel Roviras \\ TeSA-ENSEEIHT \\ Toulouse, France
}

\begin{abstract}
With the increase of global satellite navigation systems (GNSS) in a limited number of frequency bands, the current spectrum dedicated to satellite navigation encounters congestion. A possible path to keep modernizing the different GNSS is to find new frequency bands where a satellite radionavigation service (RNSS) could be provided. This article takes a regulatory approach to identify potential candidate bands, which are then reviewed in detail to assess their usability for a new RNSS deployment. The results of this analysis are: (1) there exist spaces in the spectrum where a RNSS allocation exists or could be added. For example, the option consisting in adding another RNSS allocation into aeronautical radio-navigation service (ARNS) bands. However, such allocation change is not planned and would require important commitment from administrations and long negotiations with the civil aviation community; (2) the use of telecommunication signals of opportunity coming from an hybrid satellite-terrestrial network of emitters. Among these solutions, some would permit to combine navigation and telecommunication services, offering a huge opportunity for mass market application.
\end{abstract}

Keywords-GNSS evolution, spectrum management, hybrid systems

\section{INTRODUCTION}

The different Global Navigation Satellite Systems (GNSS) are using the band allocated by the International Telecommunication Union (ITU) to the Radio-Navigation Satellite Service (RNSS). Current RNSS allocations in use are reminded in Table I along with the existing or planned systems:

TABLE I. RNSS DOWNLINK ALLOCATIONS

\begin{tabular}{|c|c|c|}
\hline $\begin{array}{c}\text { Frequency } \\
\text { (MHz) }\end{array}$ & Designation & Existing or planned systems \\
\hline $1164-1215$ & L5 & GPS, Galileo, Glonass, Compass, QZSS, \\
IRNSS
\end{tabular}

Most of the existing and planned GNSS are using the Lband $(1-2 \mathrm{GHz})$, which thus becomes more and more congested. Notably, this has led to long negotiations between the European Union and the United States before the agreement on a new modulation of the modernised GPS and Galileo signals to ensure compatibility and inter-operability between the two systems [1].

One of the possible ways for the evolution of GNSS is to provide a navigation service in a new frequency band. In our paper, we will consider the S-band (2 - $4 \mathrm{GHz})$ and C-band (4 $8 \mathrm{GHz})$.

This paper is organised as follows: in section II, the different methods to deploy a new satellite positioning service will be reviewed from a regulatory point of view. This will provide an initial list of potential candidate bands. Then, in section III, each candidate band will be reviewed to assess the possibility and the requirements to deploy a new positioning service. The conclusion will be a filtered list of the potential candidates.

\section{REGULATORY CONSTRAINTS TO DEPLOY A NEW SATELLITE POSITIONING SERVICE}

From a regulatory point of view, there are three possibilities to deploy a new satellite positioning service:

(1) Use existing RNSS bands;

(2) Add a new RNSS allocation in an existing band;

(3) Use signals of opportunity.

Service allocations to a given band is a process taking place at the ITU's World Radio-communications Conferences (WRC), which take place every 3 or 4 years and gather basically every member state of the United Nations, plus some companies or particular communities (such as the amateur radio-astronomers or the civil aviation).

Concerning solution (1), two downlink RNSS bands already exist in the S- and C-bands. $5010-5030 \mathrm{MHz}$ was obtained at the 2000 WRC [2] and confirmed at the 2003 WRC [3] as a worldwide allocation. $2483.5-2500 \mathrm{MHz}$ is allocated to Radio-Determination Satellite Service (RDSS, which is 
equivalent to RNSS), but only in the ITU Regions 2 (Americas) and 3 (Asia-Pacific).

Possibility (2) has already been encountered for the modernization of GPS and the preparation of Galileo. Indeed, RNSS was added in the 1164 - $1215 \mathrm{MHz}$ band to the existing Aeronautical Radio-Navigation Service (ARNS). Sharing spectrum with an aeronautical service permits to benefit from strong protection criteria against interferences, and to potentially deploy a safety-related RNSS service. Currently, two bands have an exclusive ARNS allocation: $2.7-2.9 \mathrm{GHz}$ (used by radars) and $4.2-4.4 \mathrm{GHz}$ (used by radio-altimeter) [4].

Finally, solution (3) is a radically different way to tackle the issue, since it is a manner to escape from regulatory constraints. Indeed, it is allowed to use telecommunication signals for position determination purpose, as long as the initial telecommunication service remains operational. Therefore, every telecommunication band would be potentially interesting for our problem, but for geometry considerations, we will limit our review to hybrid satellite-terrestrial systems, which are allowed (among others) in the 2170 - $2200 \mathrm{MHz}$ and 2483.5 $2500 \mathrm{MHz}$ bands allocated to Mobile Satellite Service (MSS). We can note that the latter band is also allocated to RDSS.

The initial list of candidate system is summarized below:

- $\quad$ Existing RNSS or RDSS bands

- $2483.5-2500 \mathrm{MHz}$ in Region 2 \& 3 only

○ 5010 - $5030 \mathrm{MHz}$ worldwide

- $\quad$ ARNS bands, necessitating a change of allocation

○ $2700-2900 \mathrm{GHz}$ used by radars

- $4200-4400 \mathrm{GHz}$ used by radio altimeters

- Opportunistic use of hybrid satellite-terrestrial MSS bands

$$
\begin{array}{ll}
\text { ○ } & 2170-2200 \mathrm{GHz} \\
\circ & 2483.5-2500 \mathrm{GHz}
\end{array}
$$

\section{REVIEW OF THE CANDIDATE BANDS}

\section{A. Existing RNSS bands}

\section{1) C-band: $5010-5030 \mathrm{MHz}$}

This existing C-band allocation was obtained at WRC-2000 with other frequency bands attributed to Galileo, but it was not used for the design of the first generation of Galileo, due to technical difficulties, notably a $10 \mathrm{~dB}$ loss on the link budget due to higher free space loss and rain attenuations, and increased phase noise affecting the pseudo-range measurement [5].

There are also strong regulatory constraints affecting the adjacent bands [6]: the aggregate power flux density at Earth surface from all RNSS satellites emitting in this band shall not exceed:

- $\quad-124.5 \mathrm{~dB}\left(\mathrm{~W} / \mathrm{m}^{2}\right)$ in a $150 \mathrm{kHz}$ band in the upper band $(5030$ - $5150 \mathrm{MHz})$, where the aeronautical Microwave Landing Systems are used;
- $\quad-196.5 \mathrm{~dB}\left(\mathrm{~W} / \mathrm{m}^{2}\right)$ in a $10 \mathrm{MHz}$ band in the lower band (4990 - $5000 \mathrm{MHz}$ ), dedicated to RadioAstronomy Services.

Moreover, the presence of an RNSS uplink allocation in the adjacent 5000 - $5010 \mathrm{MHz}$ band could cause some interference at the ground stations and the satellites, adding some constraints (isolation between uplink and downlink) to the design of some navigation signals in this band.

At the last WRC in November 2007, this band has been claimed by the Federal Aviation Administration to be used for an Aeronautical Mobile (Route) Service, to deploy a safetyoriented communications between aircraft and the ground. This allocation change is at the agenda of the next WRC which will take place in 2011 [7].

For this reason, interest in this band has improved, and the European Space Agency (ESA) has decided to support specific studies on the use of this band for satellite navigation in its GNSS Evolution Programme.

The challenge of this band is to design a system with more gain, to compensate the link budget loss, while respecting the different interference constraints in the adjacent bands. One solution studied by ESA to regain the power lost during the propagation would be to use more focused beams, which would illuminate different partial region of Earth successively. This technique is called beam-hopping and early performances can be found in [8].

Also, thanks to the shorter wavelength, multiple antennas could be used at the receiver, thus paving the way to the use of smart antenna techniques such as beamforming for satellite tracking or for multipath mitigation in order to improve the link budget.

2) S-band: $2483.5-2500 \mathrm{MHz}$

As shown in Table II, RDSS is allocated in this band in ITU region 2 (Americas) and 3 (Asia Pacific) only. That is why this band is used by or planned for regional navigation systems, such as the existing Chinese Beidou or the future Indian Regional Navigation Satellite System [9]. However, at the last WRC'07, European delegations claimed to consider the extension of this RDSS allocation all over the world. This would imply to study the compatibility with other systems sharing the band, including Globalstar.

TABLE II. SERVICE ALLOCATION IN 2483.5 - 2500 MHz (AS OF 2003)

\begin{tabular}{|l|l|l|}
\hline \multicolumn{1}{|c|}{ Region 1 Table } & \multicolumn{1}{c|}{ Region 2 Table } & \multicolumn{1}{c|}{ Region 3 Table } \\
\hline & FIXED & FIXED \\
FIXED & MOBILE & MOBILE \\
MOBILE & $\begin{array}{l}\text { MOBILE-SATELLITE } \\
\text { (space-to-Earth) }\end{array}$ & $\begin{array}{l}\text { MOBILE-SATELLITE } \\
\text { (space-to-Earth) }\end{array}$ \\
MOBILE-SATELLITE & RADIOLOCATION & RADIOLOCATION \\
Radiolocation & RADIODETERMINATION- & Radiodetermination-satellite \\
& SATELLITE & (space-to-Earth) \\
& (space-to-Earth) & \\
\hline
\end{tabular}

One of the big advantages of this band is that it is either used by telecommunication systems (Globalstar) and close to other telecommunication bands (e.g. UMTS at $2.1 \mathrm{GHz}, \mathrm{WiFi}$ at $2.4 \mathrm{GHz}$ ). A navigation signal in this band would permit to design simple mass market receiver providing both 
telecommunication and navigation services with the same RF head.

\section{B. ARNS bands - 2.7 - $2.9 \mathrm{GHz}$ and $4.2-4.4 \mathrm{GHz}$}

As stated before, RNSS has already been added to ARNS bands for the modernization of GPS (L5) or for the introduction of Galileo (E5). The sharing with ARNS implies that compatibility must be ensured, so that ARNS systems, often safety-critical for civil aviation, are not disturbed by the new RNSS signals. Some studies in L5 [10] have shown the need to reallocate the working frequencies of some ARNS equipment, which is accepted with difficulty by the aeronautical community.

Two bands are potentially interesting due to their exclusive ARNS allocation worldwide: the $2.7-2.9 \mathrm{GHz}$ (radars) and 4.2 - 4.4 GHz (radio-altimeters) [4].

These bands have a very large bandwidth, and the signals used in them are pulsed. This could potentially leave space for compatible extra-wideband navigation signals permitting greater accuracy than today's planned signals. Also, the new navigation signals would benefit from the strong protection criteria reserved for safety-critical services, which would permit to provide a complementary signal to the current "safety-of-life" navigation signals planned in GPS and Galileo.

Nevertheless, RNSS has been (and will be) generously awarded spectrum at the last WRCs (in 2000 for Galileo and in 2011 with the 2483.5 - $2500 \mathrm{MHz}$ band), whereas ARNS band has often been claimed for other services. In particular, the radar band has been coveted by mobile communication operators, since the pulsed nature of the radar signals makes it non-optimally used (by telecommunication operator's standards). At WRC 2000, that band was discussed to be considered as an extension band for IMT-2000 under agenda item 1.6, but an allocation change was refused.

Currently, no such allocation change is planned in either band. In addition, the need for a new "safety-of-life" signal is currently difficult to justify, since new dedicated signals (GPS L5 and Galileo E5) are going to be introduced in the next few years. These arguments would eliminate the considered ARNS bands from the potential candidates.

\section{Opportunistic use of hybrid satellite-terrestrial MSS bands}

The last identified possibility to offer a new navigation service would be to use telecom signals of opportunity to determine the receiver's position. This has already been done using various telecommunication signals, such as $\mathrm{WiFi}$, television [11] or 3G [12]. Nevertheless, [13] has shown that existing mobile communication networks (3G network in [13]) have bad geometric performances, and would alter the position accuracy whatever the performances of the signal and associated processing are.

Those bad geometric performances are inherent to the use of terrestrial telecommunication signals for navigation purpose. Indeed, a well-designed telecommunication network would cover the service area with the minimum number of base stations (ideally only one BS in visibility all over the service area), whereas for navigation, at least 3 or 4 emitters are required to solve the navigation problem.

This is why hybrid satellite-terrestrial systems are envisaged, since they provide inherent redundancy of emitters, with a potentially very good geometry, with BS toward the horizon and the satellite at high elevation.

Different hybrid systems are planned, with notably the 2170 - $2200 \mathrm{MHz}$ MSS allocation being allowed by the European Commission to transmit signals from complementary ground component (CGC). Similar decision was made in the US for this band (2170 - $2200 \mathrm{MHz})$, and also for different bands, such as the one reserved to satellite digital audio radio satellite (SDARS) systems $(2310-2345 \mathrm{MHz})$ and for different MSS systems, including Globalstar (2483.5 - $2500 \mathrm{MHz})$.

This regulatory flexibility and the number of planned hybrid system make this possibility quite seducing. In addition, one could imagine innovative service hybridation where telecommunication would help navigation (through the efficient transfer of data, similar to Assisted GPS) and inversely (location-assisted hand-offs or radio resource management, fine synchronization of terminals, etc.).

Still, the synchronization properties of the used signals and modifications in the different systems would be required in order to provide good navigation performances.

TABLE III. SUMMARY OF ADVANTAGES AND DRAWBACKS OF THE CONSIDERED BANDS

\begin{tabular}{|c|c|c|}
\hline Band & Advantages & Drawbacks \\
\hline $\begin{array}{c}\text { RDSS / MSS } \\
2483.5-2500 \mathrm{MHz}\end{array}$ & $\begin{array}{l}\text { - } \quad \text { Possible worldwide allocation in } 2011 . \\
\text { - } \quad \text { Possible synergy with telecommunication service. }\end{array}$ & - Compatibility with existing telecommunication systems. \\
\hline $\begin{array}{c}\text { RNSS } \\
5010-5030 \mathrm{MHz}\end{array}$ & $\begin{array}{ll}\text { - } & \text { Existing worldwide allocation. } \\
\text { - Smart antenna techniques. }\end{array}$ & $\begin{array}{ll}\text { - } & \text { Attenuation. } \\
& \text { Interference from adjacent uplink. }\end{array}$ \\
\hline $\begin{array}{c}\text { ARNS } \\
2700-2900 \mathrm{MHz}\end{array}$ & $\begin{array}{ll}\text { - } & \text { Large bandwidth. } \\
\text { - } & \text { Possible Safety-of-Life service. } \\
& \text { Pulsed emission of radars. }\end{array}$ & $\begin{array}{l}\text { - } \quad \text { Service allocation change required at ITU. } \\
\text { - Severe compatibility constraints required by civil aviation. }\end{array}$ \\
\hline $\begin{array}{c}\text { ARNS } \\
4200-4400 \mathrm{MHz}\end{array}$ & $\begin{array}{ll}\text { - } & \text { Large bandwidth. } \\
\text { - } & \text { Possible Safety-of-Life service. } \\
& \text { Localised use of radio-altimeter near airports. }\end{array}$ & $\begin{array}{l}\text { - } \quad \text { Service allocation change required at ITU. } \\
\text { - Severe compatibility constraints required by civil aviation. }\end{array}$ \\
\hline $\begin{array}{c}\text { MSS } \\
2170-2200 \mathrm{MHz}\end{array}$ & $\begin{array}{l}\text { - } \quad \text { Existing world allocation. } \\
\text { Use of terrestrial emitters in the same band as the satellite } \\
\text { emitters. } \\
\text { - Synergy with telecommunication service. }\end{array}$ & $\begin{array}{l}\text { - Use of telecommunication signals to determine the user's } \\
\text { position. } \\
\text { Radio-planning for telecommunication may be incompatible } \\
\text { with navigation geometric requirements. }\end{array}$ \\
\hline
\end{tabular}




\section{IV.CONCLUSION}

From a basic regulatory analysis, we have identified 3 groups of candidate band for the deployment of new satellite navigation service. Among these, the ARNS bands seems the less convincing, principally due to the difficulty to obtain a change of service allocation in aeronautical bands, but also because the GNSS community has already obtained large part of spectrum recently (and still is).

One of the remaining groups is RNSS bands. The 5010 $5030 \mathrm{MHz}$ band is under study but may encounter serious difficulties due to interferences coming from an adjacent RNSS uplink band and unfavorable link budget at this frequency. Nevertheless, the innovation potential of this band is important, notably by the possibility to use smart antenna technologies.

The 2483.5 - $2500 \mathrm{MHz}$ band is shared with different systems and the current allocation to only 2 regions of the world will likely be changed to worldwide allocation after WRC-2011, should sharing criteria be accepted by the other existing systems. There is great potential for this band, notably due to the proximity of the telecommunication signals, which would permit navigation and telecommunication service hybridation in a mass market terminal. With the presence of the Globalstar worldwide mobile satellite telecommunication system in the same band, such hybridation would provide a unique opportunity, both in terms of provided service and service coverage.

The other candidate group would employ telecommunication signals of opportunity in order to determine the receiver's position. For geometry and availability reasons, hybrid satellite-terrestrial systems should provide an attractive opportunity, if fine time synchronization can be obtained from the used telecommunication waveforms. Code-Division Multiplexing Access-using signals will provide good synchronization performances, which is still to be poved for Orthogonal Frequency Division Multiplexing signals, which are foreseen to be used on many next generation systems. Choosing such solution would nevertheless require a major overhaul of the telecommunication systems, with a dedicated control segment to monitor the satellites' orbits, stable (atomic) clock on-board the spacecrafts and a capacity robbing of the available data transfer capacity. Further studies are required to assess the trade-off between the interest and the additional cost and complexity of such system.

\section{REFERENCES}

[1] Avila-Rodriguez JA, Hein GW, Wallner S, Issler JL, Ries L, Lestarquit L, et al. The MBOC Modulation, a Final Touch for the Galileo Frequency and Signal Plan. Inside GNSS. 2007 September;2(6):43-58.

[2] Final Acts - WRC-2000, Istanbul

[3] Final Acts - WRC-03, Geneva

[4] Hein G. W., Avila-Rodriguez J.-A., Wallner S., Eissfeller B., Isigler M. and Issler J.-L. A vision on new frequencies, signals and concepts for future GNSS systems, ION GNSS 2007.
[5] Irsigler M, Hein GW, Eissfeller B, Schmitz-Peiffer A, Kaiser M, Hornbostel A, et al. Aspects of C-Band Satellite Navigation: Signal Propagation and Satellite Signal Tracking. In: European Navigation Conference ENC-GNSS 2002; 2002.

[6] Zanier F, Crisci M, Luise M. Signal design criteria and parametric analysis for next generation C-band satellite navigation system. In: European Navigation Conference ENC-GNSS 2008.

[7] ITU Administrative Circular CA/171. Results of the first session of the Conference Preparatory Meeting for WRC 11

[8] Colzi E, Lòpez-Risueño G, Samson J, Angeletti P, De Gaudenzi R, Gerner JL. A System-Level Approach to the Feasibility Assessment of GNSS in C-band. In: European Navigation Conference ENCGNSS 2008; 2008.

[9] SATNAV Industry Meet. In: Space India, April-September 2006.

[10] Hegarthy C, Kim T, Ericson S, Reddan P, Van Dierendonck AJ. Methodology for Determining Compatibility of GPS L5 with Existing Systems and Preliminary Results. In: ION Annual Meeting; 1999.

[11] Rabinowitz M, Spilker JJ. A new positioning system using television synchronization signals. In: IEEE Transactions on Broadcasting, Vol. 51, No. 1. (2005), pp. 51-6; 2005.

[12] Zhao Y. Standardization of mobile phone positioning for $3 \mathrm{G}$ systems. In: Communications Magazine, IEEE, Vol. 40, No. 7. (2002), pp. 108-116; 2002.

[13] Hein G, Eissfeller B, Oehler V, Winkel JO. Synergies between Satellite Navigation and Location Services of Terrestrial Mobile Communication. In: ION GPS 2000; 2000. p. 535-544. 